\title{
Surface Chemistry of Copper(I) Acetamidinates in Connection with Atomic Layer Deposition (ALD) Processes
}

\section{Citation}

Ma, Qiang, Hansheng Guo, Roy G. Gordon, and Francisco Zaera. 2011. Surface chemistry of copper(I) acetamidinates in connection with atomic layer deposition (ALD) Processes. Chemistry of Materials 23(14): 3325-3334.

\section{Published Version}

doi: $10.1021 / \mathrm{cm} 200432 \mathrm{t}$

\section{Permanent link}

http://nrs.harvard.edu/urn-3:HUL.InstRepos:11169838

\section{Terms of Use}

This article was downloaded from Harvard University's DASH repository, and is made available under the terms and conditions applicable to Open Access Policy Articles, as set forth at http:// nrs.harvard.edu/urn-3:HUL.InstRepos:dash.current.terms-of-use\#OAP

\section{Share Your Story}

The Harvard community has made this article openly available.

Please share how this access benefits you. Submit a story.

\section{Accessibility}




\title{
Surface Chemistry of Copper(I) Acetamidinates in Connection with
}

\section{Atomic Layer Deposition (ALD) Processes}

Qiang Ma, ${ }^{1}$ Hansheng Guo, ${ }^{1}$ Roy G. Gordon, ${ }^{2}$ and Francisco Zaera ${ }^{1}$ *

${ }^{1}$ Department of Chemistry, University of California, Riverside, CA 92521, USA

${ }^{2}$ Department of Chemistry and Chemical Biology, Harvard University, Cambridge, MA 02138, USA

*Email: zaera@ucr.edu

\begin{abstract}
The thermal chemistry of copper(I)- $N, N^{\prime}$-di-sec-butylacetamidinate on Ni(110) single-crystal and cobalt polycrystalline surfaces was characterized under ultrahigh vacuum (UHV) conditions by X-ray photoelectron spectroscopy (XPS) and temperature-programmed desorption (TPD). A complex network of reactions were identified, starting with the dissociative adsorption of the precursor, from its dimeric form in its free state to a monomer once bonded to the nickel surface. The dissociation of a $\mathrm{C}-\mathrm{N}$ bond in the acetamidinate ligand at $\sim 200 \mathrm{~K}$ leads to the formation of adsorbed 2-butene and $\mathrm{N}$-sec-butylacetamidinate. Some of the latter intermediate hydrogenate around $300 \mathrm{~K}$ to release $\mathrm{N}$-sec-butylacetamidine into the gas phase, while the remaining adsorbed species dissociate further around $400 \mathrm{~K}$, as the copper atoms become reduced to a
\end{abstract}


metallic state, possibly to form acetonitrile and a sec-butylamido surface species that reacts further at $485 \mathrm{~K}$ to release 2-butene. By $800 \mathrm{~K}$, only copper and a small amount of carbon can be seen on the surface by XPS. The implications of this chemistry to the growth of metal films by atomic layer deposition (ALD) are discussed.

Keywords: Atomic Layer Deposition, Copper Films, Surface Chemistry, X-ray Photoelectron Spectroscopy, Amidinate Complex

\section{Introduction}

Given the high stability of amidines, they have long been considered good choices as bidentate ligands in organometallic compounds. Early uses of metal amidinates have been reported in catalysis, to promote polymerizations and other related reactions. ${ }^{1-3}$ More recently, metal amidinates have been developed as promising precursors for the deposition of solid thin films. ${ }^{4-8}$ They have proven particularly useful in atomic layer deposition (ALD) processes, where the surface chemistry of film growth is split into two self-limiting and complementary half-reactions in order to control the deposition at a monolayer level. ${ }^{9-11}$ Ideally, the metal-based precursor in metal ALD processes should adsorb on the substrate until saturation of a monolayer, preferably retaining the structure of most if not all of its ligands intact, after which a second reactant is introduced to remove those ligands and to activate the surface for the next ALD cycle. 
Unfortunately, most organometallic precursors used in ALD do show some secondary thermal chemistry involving the conversion of the ligands during adsorption into new surface species. This is often undesirable, because the new adsorbates may bind strongly to the surface and remain there even after exposures to the second reactant. Such side reactions are the most common source of impurities in the films grown by chemical means, and the reason why stable ligands are sought for these applications. In the case of amidinates ligands, for instance, the hope is that those moieties survive the first half of the cycle so they can be hydrogenated to the corresponding amidine in the second half.

To date, though, not much is known about the chemistry of either metal amidinates or amidines on solid surfaces. An infrared absorption study on the chemistry of lanthanum(III)-tris- $N, N^{\prime}$-diiso-propylacetamidinate on a hydrogen-terminated $\mathrm{Si}(111)$ surface indicated the incorporation of acetate/carbonate and hydroxyl impurities in the growing films. ${ }^{12}$ It was also established in that work that deposition at $573 \mathrm{~K}$, a temperature low enough to prevent the formation of interfacial $\mathrm{SiO}_{2}$, leads to decomposition of the adsorbed ligands and the formation of cyanamide or carbodiimide surface species. Analogous chemistry has also been proposed for the gas-phase chemistry of a related copper guanidimate compound. ${ }^{13}$

A more recent report on the surface chemistry of copper(I)-N,N'-di-sec-butylacetamidinate on $\mathrm{SiO}_{2}$ shows a cleaner surface chemistry, with initial adsorption occurring via displacement of one of the ligands at a surface hydroxide site. ${ }^{14}$ According to that work, subsequent exposure to molecular hydrogen leads to the hydrogenation of most of the remaining $N, N^{\prime}$-di-secbutylacetamidinates to free $N, N^{\prime}$-di-sec-butylacetamidine vapor. Reattachment of some of the 
released acetamidine to the $\mathrm{SiO}_{2}$ surface was suggested as the source of the carbon contamination seen during the initial cycles of growth. Finally, our initial work on the deposition of the same copper precursor on a Ni(110) single-crystal surface identified a temperature window between approximately 350 and $450 \mathrm{~K}$ for the deposition of the precursor on the surface: lower temperatures are insufficient for activation of the dissociative adsorption, and higher temperatures lead to continuous decomposition beyond $\mathrm{Cu}$ monolayer saturation. ${ }^{15}$ That study also suggested more complex surface chemistry than on $\mathrm{SiO}_{2}$. Here, we provide further details on the thermal conversions involved.

\section{Experimental Details}

The experiments were conducted in an ultrahigh vacuum (UHV) system turbo-pumped to a base pressure of $1 \times 10^{-10}$ Torr and equipped with an UTI mass quadruple for temperature programmed desorption (TPD), a concentric hemispherical analyzer (VG 100AX) and an $\mathrm{Al} \mathrm{K}_{\alpha} / \mathrm{Mg} \mathrm{K}$ dual anode X-ray source for X-ray photoelectron spectroscopy (XPS), and a Kratos rasterable rare-gas ion gun for sample cleaning. ${ }^{16}$ The XPS data were taken by using the $\mathrm{Al} \mathrm{K} \mathrm{K}_{\alpha}$ X-ray source $(\mathrm{h} v=$ $1486.6 \mathrm{e} \mathrm{V}$ ), with a total resolution of approximately $1.0 \mathrm{eV}$. No evidence of X-ray damage was observed: similar results were obtained regardless of the time of exposure to the X-rays, and the same molecular desorption behavior was observed in TPD before versus after radiation. The raw data were analyzed by using deconvolution software in order to identify the different components of the overall signals in the spectra of each element. Shirley background subtraction was carried out first when needed, after which Gaussian peaks were fitted. The binding energies 
and widths for a given element were fixed across the data sets versus annealing temperature in order to minimize the number of adjustable parameters.

A polished $\mathrm{Ni}(110)$ single-crystal was used as the substrate for most of the experiments, except for those reported in Figure 8, which were performed with a cobalt polycrystalline foil. Both samples were used in the form of disks approximately $10 \mathrm{~mm}$ in diameter and $1 \mathrm{~mm}$ in thickness, and were mounted on a vacuum manipulator via $0.5 \mathrm{~mm}$ Ta-wires spot-welded to the edge of the crystal and fixed to the ends of copper vacuum feedthroughs. Cooling was accomplished by using a liquid-nitrogen reservoir in direct contact with the copper feedthroughs, and resistive heating was used to reach any desired temperature between 90 and $1200 \mathrm{~K}$. A K-type thermocouple was spot-welded to the edge of the crystal to monitor the temperature of the surface, and a homemade temperature controller was used to provide linear temperature ramps for the TPD experiments and to maintain the crystal to within $\pm 1 \mathrm{~K}$ of any specified temperature. The heating rate for the TPD measurements was set to $10 \mathrm{~K} / \mathrm{s}$. Annealing of the adsorbed layers to the temperatures indicated in the XPS data was accomplished by heating the crystal to the desired temperature at a rate of approximately $20-30 \mathrm{~K} / \mathrm{s}$ and then holding that temperature for a couple of minutes. Both the $\mathrm{Ni}(110)$ crystal and the polycrystalline cobalt foil were cleaned before each experiment by repeated cycles of $\mathrm{Ar}^{+}$ion sputtering and annealing at $1100 \mathrm{~K}$ until the surface was deemed clean by XPS.

The copper(I)-N,N'-di-sec-butylacetamidinate precursor was synthesized by sequential reactions of $N, N^{\prime}$-di-sec-butylacetamidine with $\mathrm{CH}_{3} \mathrm{Li}$ and $\mathrm{CuCl}$; the free $N, N^{\prime}$-di-sec-butylacetamidine was prepared by reaction of acetonitrile with $N$-sec-butylamine. ${ }^{17}$ All gases were purchased 
from Liquid Carbonic (Research Purity, >99.995\%), and used without further treatment. Dosing of the sample was done by backfilling of the chamber using leak valves; in the case of the copper(I)-N,N'-di-sec-butylacetamidinate precursor, the gas line was heated to approximately $330 \mathrm{~K}$ in order to minimize condensation. Gas doses are reported in Langmuirs $\left(1 \mathrm{~L}=1 \times 10^{-6}\right.$ Torr $\cdot \mathrm{s})$, uncorrected for differences in ion gauge sensitivities. The pressure in the main UHV chamber was measured using a nude ion gauge.

\section{Results}

The thermal chemistry of copper(I)- $N, N^{\prime}$-di-sec-butylacetamidinate on the $\mathrm{Ni}(110)$ single-crystal surface was first explored by using X-ray photoelectron spectroscopy (XPS). The raw data obtained after dosing $50 \mathrm{~L}$ of the precursor at $90 \mathrm{~K}$ is shown as a function of annealing temperature, all the way to $800 \mathrm{~K}$, in Figures $1\left(\mathrm{Cu} 2 \mathrm{p}_{3 / 2} \mathrm{XPS}\right.$, left, and $\mathrm{Cu} \mathrm{L}_{3} \mathrm{VV}$ AES, right) and 2 ( $\mathrm{N}$ 1s XPS, left, and $\mathrm{C} 1 \mathrm{~s}$ XPS, right). Figure 4 summarizes the data in terms of peak intensities versus annealing temperature for the different features deconvoluted from the raw data, and Tables 2 and 3 summarize the parameters used in the fits for the $\mathrm{N} 1 \mathrm{~s}$ and $\mathrm{C} 1 \mathrm{~s}$ traces, respectively. Additional reference spectra are provided in Figure 3, as discussed below.

In terms of the behavior of the copper signal (Figure 1), only two types of copper atoms were identified here. The first type is clear in the spectra obtained after annealing at temperatures below $300 \mathrm{~K}$, with the $\mathrm{Cu} 2 \mathrm{p}_{3 / 2}$ XPS peak centered at $934.1 \mathrm{eV}$ and the $\mathrm{Cu}_{3} \mathrm{VV}$ AES signal at 913.8 eV, which amounts to an Auger parameter $\left(\mathrm{BE}\left(\mathrm{Cu} 2 \mathrm{p}_{3 / 2}\right)+\mathrm{KE}\left(\mathrm{Cu} \mathrm{L} \mathrm{L}_{3} \mathrm{VV}\right)-\mathrm{h} v\right)$ of 361.3 
$\mathrm{eV}$, a value typical for $\mathrm{Cu}(\mathrm{I}){ }^{18}$ That signal is therefore easily identified with the original copper precursor, although we believe that the dimeric form that exists in the gas phase does dissociate into monomeric units upon adsorption (see below). The second state is seen above $500 \mathrm{~K}$, and is characterized by $\mathrm{Cu} 2 \mathrm{p}_{3 / 2}$ XPS and $\mathrm{Cu} \mathrm{L}_{3} \mathrm{VV}$ AES signals at 932.5 and $919.0 \mathrm{eV}$, respectively, and an Auger parameter of $364.9 \mathrm{eV}$, the value expected for metallic copper. ${ }^{18}$ The transition from $\mathrm{Cu}(\mathrm{I})$ to $\mathrm{Cu}(0)$ occurs around $400 \mathrm{~K}$, at which point components for both oxidation states are seen in both XPS and AES peaks. No transitions other than the transformation from $\mathrm{Cu}(\mathrm{I})$ to $\mathrm{Cu}(0)$ were ever detected here, ruling out the possible disproportionation reaction of the precursor or any other conversion that would produce $\mathrm{Cu}(\mathrm{II})$ on the surface. In terms of the intensities of the peaks, the size of the $\mathrm{Cu}(\mathrm{I})$ peak first increases between 200 and $250 \mathrm{~K}$, indicating desorption of the excess copper(I)-N,N'-di-sec-butylacetamidinate condensed in the multilayer, as corroborated by the TPD data reported below (the organic ligands in the multilayer partially screen the copper photoelectrons). Also, a slight progressive growth in the XPS signal for $\mathrm{Cu}(0)$ is observed as a function of annealing temperature, presumably because of a further increase in exposure of the copper atoms as other molecules desorb from the surface.

The changes seen in the N 1s and C 1s XPS peaks upon annealing of the surface are somewhat more complex. In the case of the nitrogen signal, the XPS trace obtained at $150 \mathrm{~K}$, presumably due to the molecularly adsorbed precursor, is quite broad, and likely composed of two or more peaks (Figure 2). Deconvolution of that spectrum yielded two Gaussian peaks centered at 398.65 and $400.15 \mathrm{eV}$ with approximately similar intensities (Table 1). This points to the presence of two different types of nitrogen atoms within the adsorbed copper acetamidinate, strongly suggesting the dissociation of the original dimer, where all nitrogen atoms are in the same 
environment, ${ }^{17}$ upon bonding to the surface. In order to further highlight the changes that take place upon adsorption of the copper acetamidinate onto the $\mathrm{Ni}(110)$ surface, reference XPS data were acquired for the condensed copper acetamidinate precursor and for $N, N^{\prime}$-di-secbutylacetamidine, the free ligand. The results are shown in Figure 3. Since the copper precursor is a liquid, direct acquisition of its XPS was not possible. Instead, spectra were acquired for several increasing doses of the compound onto the nickel substrate held at $90 \mathrm{~K}$, and the difference traces used to extract information about the condensed layers (after subtracting the component from the first adsorbed monolayer). The data in the left panel of Figure 3 clearly indicate that the condensed multilayer of the copper acetamidinate displays one single feature, the one at low binding energy $(398.65 \mathrm{eV})$ : only that component is evident in the traces obtained after subtracting from the trace for $50 \mathrm{~L}$ of copper acetamidinate adsorbed at $90 \mathrm{~K}$ the data for either $15 \mathrm{~L}$ of copper acetamidinate, also adsorbed at $90 \mathrm{~K}$, or the surface dosed with $50 \mathrm{~L}$ of copper acetamidinate and then annealed to $150 \mathrm{~K}$ (to remove the multilayer). One single $\mathrm{N} 1 \mathrm{~s}$ XPS peak is what is expected from the original copper acetamidinate, since, as indicated above that molecule exists in a dimeric form with all four nitrogen atoms in equivalent chemical environments. Also worth highlighting here is the fact that the spectrum for adsorbed amidine does display significant signals for both binding energies, indicating the different nature of the two nitrogen atoms in that molecule, as is the case of the copper amidinate once adsorbed on the $\operatorname{Ni}(110)$ crystal.

The C 1s XPS spectra are even more complex than those for nitrogen, given the diversity of carbon bonding types present in acetamidinate ligands. Although our instrument does not have the resolution to separate the signals from all those different types of carbon, the $\mathrm{C} 1 \mathrm{~s}$ XPS traces 
for the low-temperature adsorbed precursor are clearly skewed toward the high-binding-energy side of the spectra (Figures 2 and 3). Three components were extracted upon deconvolution by fixing the relative areas to follow ratios of 7:2:1 (in order to minimize the number of fitting parameters and obtain chemically meaningful results), centered at 285.4 (alkyl carbons), 286.4 (amido carbons), and 287.5 (amidine carbon) eV, respectively (Table 2). The results of such deconvolution are shown for 15 and $50 \mathrm{~L}$ doses of the copper acetamidinate and for $50 \mathrm{~L}$ of the free acetamidine ligand, all adsorbed on the $\mathrm{Ni}(110)$ surface at $90 \mathrm{~K}$, in Figure 3 (right) The effect on the carbon atoms of any potential asymmetry induced by the bonding of the acetamidine to the copper is expected to be subtle, and could not be extracted from the data reported here. What is also clear from the traces in Figure 3 is that the main change observed upon desorption of the multilayer of the copper acetamidinate is a loss in signal for the C 1s XPS feature associated with the alkyl carbons (most evident in the difference traces shown at the top). This suggests that the ligands adopt a preferential geometry in the first monolayer, with the amido and amidine carbon more exposed relative to the alkyl carbons.

To analyze the N 1s and C 1s XPS spectra obtained after annealing at temperatures above $200 \mathrm{~K}$, the combined peaks for the acetamidine moieties were first subtracted from the data by using the fits shown in Figure 3, appropriately scaled. A monotonic decrease in that contribution is seen for both nitrogen and carbon atoms from $200 \mathrm{~K}$ to approximately $500 \mathrm{~K}$, at which point only about $\sim 5 \%$ of that signal is left (Figure 4). This trend matches the decrease in $\mathrm{Cu}(\mathrm{I})$ signal seen in the copper XPS data, an observation that indicates that the reduction of the metal center occurs upon elimination or decomposition of the acetamidinate ligands. Displacement of the copper 
atoms by nickel atoms from the surface in the copper complex immediately upon adsorption, and coordination of the ligands to those new atoms, is ruled out by these data.

Two new features develop in the N 1s XPS spectra upon annealing of the adsorbates at $200 \mathrm{~K}$ and above (Table 1). The first is centered at values between 399.0 and $398.6 \mathrm{eV}$, and is detected at temperatures as low as $200 \mathrm{~K}$ (drifting from the high value to the low number with increasing temperature). This binding energy is close in value to that of the N 1s XPS signal for the original copper acetamidinate, and may therefore originate from a fragment of the original acetamidinate adsorbed on the nickel surface or a closely related species. We propose that this signal signifies the onset of formation of $\mathrm{N}$-sec-butylacetamidinate, a species detected in the TPD experiments (see below). A second feature then starts to develop around $397.2 \mathrm{eV}$ after annealing to $300 \mathrm{~K}$ that peaks at $400 \mathrm{~K}$. This peak is not likely to correspond to the formation of any metal nitride, the binding energy of which is typically lower, ${ }^{19}$ and is most possibly due to a new organic moiety, perhaps a nitrile $(-\mathrm{C} \equiv \mathrm{N})$ surface species. ${ }^{20}$ The $\mathrm{N}$ 1s XPS peak of acetonitrile adsorbed on $\mathrm{Ni}(111)^{21}$ and $\mathrm{Pt}(111){ }^{22}$ single-crystal surfaces has been reported at 397.7 and $397.2 \mathrm{eV}$, respectively, within the range of our observation, and a $\mathrm{C} \equiv \mathrm{N}$ surface species has been identified in the infrared spectra of a thermally-rearranged acetamidinate ligand on lanthanum oxide. ${ }^{12}$ The previous work has associated this new species with a flat adsorption geometry, with the carbonnitrogen bond rehybridized and di-sigma bonded to the metal surface. We therefore suggest, tentatively, that the $397.2 \mathrm{eV} \mathrm{N} \mathrm{1s} \mathrm{XPS} \mathrm{peak} \mathrm{observed} \mathrm{here} \mathrm{may} \mathrm{reflect} \mathrm{the} \mathrm{formation} \mathrm{of}$ adsorbed acetonitrile, even though the evidence is not compelling. It is interesting to note that the total intensity of the $\mathrm{N}$ 1s XPS signal decreases monotonically throughout the whole annealing temperature range explored here, and that the intensities of both 398.6 and $397.2 \mathrm{eV}$ 
features reach their maxima at $400 \mathrm{~K}$ and decrease afterwards; no $\mathrm{N} \mathrm{1s}$ XPS signal at all is detected after annealing to $800 \mathrm{~K}$ (within our instrumental sensitivity). In other words, all the nitrogen appears to be removed via the desorption of nitrogen-containing compounds.

The high-temperature behavior of the C 1s XPS spectra is again more complex than what is observed for the N 1s XPS data. Because of limitations in both resolution and signal intensity, only a broad analysis of these spectra can be performed here. Two new peaks are seen to evolve in the spectra starting at temperatures as low as $200 \mathrm{~K}$, the first of which is likely to represent a series of evolving species on the surface, since it shifts from $286.0 \mathrm{eV}$ at $200 \mathrm{~K}$ to $285.5-285.4$ $\mathrm{eV}$ at $300 \mathrm{~K}$ or above (Table 2). The high binding-energy $(286.0 \mathrm{eV})$ peak seen in the lowtemperature range could very well be associated with a transient amido surface species; this is the value obtained for sec-butylamine condensed on $\mathrm{Ni}(110)$ at $90 \mathrm{~K}$ (data not shown). It may, alternatively, signify the re-coordination of the original acetamidinate ligand (or a similar smaller acetamidinate, see below) to metal atoms within the surface. By $250 \mathrm{~K}$, however, this peak has shifted to $285.6 \mathrm{eV}$ already, indicating further dehydrogenation to form an imido-type species and/or fragmentation to yield a surface alkyl (or more dehydrogenated hydrocarbon) moiety; that intermediate almost entirely disappears by $300 \mathrm{~K}$. It is interesting to point out that this thermal evolution also mirrors that seen with sec-butylamine on $\mathrm{Ni(110)}$ (data not shown). A slightly shifted high-binding-energy C 1s XPS feature reappears around 285.5-285.4 eV and reaches a second intensity maximum at $400 \mathrm{~K}$, after which it decreases in size at the expense of a new signal at $284.0 \mathrm{eV}$ (Table 2). The $284.0 \mathrm{eV}$ feature appears already around $200 \mathrm{~K}$, reaches maximum coverage at $600 \mathrm{~K}$, and almost disappears by $800 \mathrm{~K}$ (Table 2), and displays a binding energy consistent with dehydrogenated hydrocarbon fragments, perhaps even graphitic carbon 
(but not nickel carbide, the binding energy of which appears at $283.0 \mathrm{eV}$ ). ${ }^{23}$ Overall, annealing to $800 \mathrm{~K}$ removes all but about $5 \%$ of the carbon signal (and all the nitrogen, as mentioned above). It should be stressed that the XPS data, specially the C 1s XPS results, are useful to identify changes on the surface, but could not be used alone to unequivocally identify individual adsorbates.

Further insight into the surface chemistry of the copper(I)- $N, N^{\prime}$-di-sec-butylacetamidinate precursor on $\mathrm{Ni}(110)$ single-crystal surfaces was obtained from temperature-programmed desorption (TPD) data. Figure 5 shows the TPD traces for the main products detected from thermal activation of a saturated adsorbed layer $(20 \mathrm{~L})$ of the copper acetamidinate initially dosed at $90 \mathrm{~K}$. Four gas-phase species could be clearly identified in these experiments: hydrogen, butene, $N$-sec-butylacetamidine, and the molecular copper(I)-N,N'-di-secbutylacetamidinate precursor. Multiple masses were used to identify these species, but those for 2, 56, 114, and $72 \mathrm{amu}$ were employed in Figures 5 and 7 to report the desorption data of the four products listed here, respectively. Many other species were sought for but not detected, including amines, imines, alkanes, other alkenes, and nitriles.

Molecular desorption occurs at approximately $215 \mathrm{~K}$. It is seen not only in the $72 \mathrm{amu}$ trace reported in Figure 5, but also in the one for 114 amu (indicated in grey in that figure). A significant amount of butene is also seen in the TPD data in Figures 5 and 7, as a broad and asymmetric peak centered around $485 \mathrm{~K}$. Butene formation is easily justified via $\beta$-hydride elimination from the terminal sec-butyl moieties of the acetamidinate ligands, as they dehydrogenate within the original ligand or in any related fragments that may form on the 
surface upon thermal activation. Hydrogen desorption is observed in several stages, with identifiable peaks centered at approximately $310,410,480$, and $580 \mathrm{~K}$, indicating stepwise dehydrogenation of the surface species formed upon decomposition of the original ligand. Finally, $\mathrm{N}$-sec-butylacetamidine desorbs in a sharp feature at $300 \mathrm{~K}$.

The formation of the latter (smaller) acetamidine can be explained by hydrogenation of the fragment left upon elimination of a terminal sec-butyl moiety from the original $N, N^{\prime}$-di-secbutylacetamidinate ligand. Nevertheless, its identification required a number of additional experiments, since no data are available on its mass spectrum. Figure 6 summarizes the key evidence obtained in our studies to support the assignment. The main frame of that figure displays TPD traces for selected masses to highlight the different cracking patterns of the species that desorb at 215 versus $300 \mathrm{~K}$. To note here is the fact that no signal was observed in the 300 $\mathrm{K}$ peak for masses higher than $114 \mathrm{amu}$, the molecular weight of the proposed $\mathrm{N}$-secbutylacetamidine $\left(\mathrm{C}_{6} \mathrm{~N}_{2} \mathrm{H}_{14}\right)$. The $215 \mathrm{~K}$ peak, by contrast, displays strong signals for higher masses, noticeably for $170 \mathrm{amu}$, the molecular mass of the hydrogenated initial ligand $\left(\mathrm{C}_{10} \mathrm{~N}_{2} \mathrm{H}_{22}\right)$. In addition, the data in the inset show the cracking pattern calculated for both desorption features (215 and $300 \mathrm{~K}$ ) in the 106-114 amu range, estimated from the areas of the corresponding TPD signals. Again, a different pattern is seen for each of the two TPD features, with a particularly higher intensity in the $300 \mathrm{~K}$ peak for the $112 \mathrm{amu}$ trace.

The evolution of the TPD traces for the main desorbing species as a function of the initial surface coverage of the copper(I)- $N, N^{\prime}$-di-sec-butylacetamidinate precursor is shown in Figure 7 . The traces for $\mathrm{H}_{2}$ (Figure 7, left) display a particularly complex behavior. The first main feature is 
seen around 300-320 K. Although the shape of that peak changes somewhat with coverage, it remains approximately the same after exposures of $2.0 \mathrm{~L}$ or above. This temperature is close to that seen for $\mathrm{H}_{2}$ desorption after dosing $\mathrm{H}_{2}$ on $\mathrm{Ni}(110),{ }^{16,}{ }^{24}$ and is therefore likely to be kinetically limited by the recombination of hydrogen surface atoms into $\mathrm{H}_{2}$, that is, it may correspond to hydrogen produced from dehydrogenation of surface species at lower temperatures. A small low-temperature shoulder is seen in some instances, probably from weakly-bonded hydrogen coadsorbed with other species. ${ }^{25,26}$ A third feature shifts to higher temperatures with increasing coverages, from 320 to $410 \mathrm{~K}$, reflecting the increasing stability of the initial intermediates as the surface becomes more crowded. The main peak at saturation is detected at $480 \mathrm{~K}$, but that feature also shifts to higher temperatures, starting from the value of about $440 \mathrm{~K}$ seen in experiments with low copper(I)- $N, N^{\prime}$-di-sec-butylacetamidinate doses. Finally, the small shoulder at $580 \mathrm{~K}$ could originate from dehydrogenation at defect sites on the surface, and most likely indicate full dehydrogenation of the $\sim 5 \%$ of carbon-containing species that remain on the surface after heating to high temperatures (see XPS data in Figures 2 and 4).

Butene desorption is only detected after exposures of $2.0 \mathrm{~L}$ or above (Figure 7, second panel from the left). This means that any butene (or other adsorbed species) that may form at lower coverages dehydrogenate fully on the surface instead of desorbing into the gas phase. This is a quite common behavior with hydrocarbons on transition metal surfaces. ${ }^{27-29}$ The butene TPD peak shifts to slightly higher temperatures with coverage, from $450 \mathrm{~K}$ for $6.0 \mathrm{~L}$ to $485 \mathrm{~K}$ at saturation. The TPD feature for the small acetamidine (the $\mathrm{N}$-sec-butylacetamidine) is also detected starting at $2.0 \mathrm{~L}$, in a peak that starts at about $270 \mathrm{~K}$ and sharpens and shifts to $300 \mathrm{~K}$ 
with increasing surface coverage (Figure 7, far right). Finally, molecular desorption starts at 6.0 L, and occurs at about $220 \mathrm{~K}$, a bit higher at lower coverages (Figure 7, second from right).

In this work we have chosen to use a nickel single-crystal surface to represent the type of metallic substrates used as barriers to prevent the diffusion of the copper films into the underlying silicon substrate. Typical materials used for this include nitrides of transition metals such titanium, tantalum, or tungsten, ${ }^{30,31}$ or a pure late transition metal such as ruthenium. ${ }^{32}$ An additional problem often arises in that copper may not adhere well to some of the diffusion barrier materials. For this reason, an adhesion layer is sometimes also added before the copper deposition, often another late transition metal such as ruthenium or cobalt. ${ }^{33,34}$ We consider nickel a good representative of the materials used for diffusion barriers and adhesion layers in copper deposition processes for microelectronic applications. To check on the generality of the conclusions derived from our work, similar experiments were also carried out on a cobalt polycrystalline foil.

The $\mathrm{N} 1 \mathrm{~s}$ and $\mathrm{C} 1 \mathrm{~s}$ XPS data obtained for the thermal behavior of the copper(I)- $N, N^{\prime}$-di-secbutylacetamidinate precursor adsorbed on cobalt is shown in Figure 8. The trends seen with this surface mirror quite closely those seen on $\mathrm{Ni}(110)$ : compare the data in Figures 2 versus 8 . In particular, both N 1s and C 1s XPS data on the Co foil highlight the same progressive decay seen on $\mathrm{Ni}(110)$ of the signals due to the original amidinate between approximately 200 and $400 \mathrm{~K}$. In the N 1s XPS data, a separate peak develops at $398.6 \mathrm{eV}$ and reaches two maxima in intensity at 200 and $400 \mathrm{~K}$, and a third feature (associated here with a nitrile intermediate) evolves around $397.2 \mathrm{eV}$ at high temperatures, peaking at $400 \mathrm{~K}$. With respect to the $\mathrm{C} 1 \mathrm{~s}$ XPS results, some 
signal in addition to what can be assigned to the original copper acetamidinate is seen as early as $200 \mathrm{~K}$, at a position that starts around $286.5 \mathrm{eV}$ but shifts to lower values upon annealing to higher temperatures. A second feature also grows at $284.0 \mathrm{eV}$ with increasing temperature, and dominates the spectra above $400 \mathrm{~K}$. All these trends match those observed on $\mathrm{Ni}(110)$.

\section{Discussion}

The experiments reported here indicate that the surface chemistry of copper acetamidinate complexes on metal surfaces may be quite complex, involving a number of intermediates and displaying a conversion in several stepwise reactions over a wide range of temperatures. The data in this report may not be sufficient to fully account for all of that chemistry, but can provide some guidelines on its main features. In the paragraphs below a discussion is provided on the thermal chemistry of copper(I)- $N, N^{\prime}$-di-sec-butylacetamidinate on $\mathrm{Ni}(110)$ single-crystal surfaces. To aid in that discussion, Figure 9 provides a schematic representation of the main reactions proposed.

The first conclusion derived from the data presented in this paper is that the chemisorption of the copper acetamidinate complex on the nickel surface is dissociative. The free complex has been reported to exist as a dimer, $\left[\left(\sec -\mathrm{C}_{4} \mathrm{H}_{9}\right) \mathrm{NC}\left(\mathrm{CH}_{3}\right) \mathrm{N}\left(\mathrm{sec}-\mathrm{C}_{4} \mathrm{H}_{9}\right) \mathrm{Cu}\right]_{2}$, with all four nitrogen atoms in similar chemical environments. ${ }^{17}$ However, upon chemisorption on the Ni(110) surface, the $\mathrm{N}$ 1s XPS data indicate the differentiation of those nitrogen atoms into two distinct types, with approximately equal populations. The data are consistent with a monomer where the amido 
nitrogen is directly bonded to the copper atom and the imido nitrogen either free or weakly interacting with the nickel surface. The fact that the acetamidinate ligand is still coordinated to the copper center is supported by the preservation of its +1 oxidation state. It is worth recalling that the N 1s XPS trace obtained after adsorption at $90 \mathrm{~K}$ also displays a more symmetrical feature, with one single component, corresponding to all the (equivalent) nitrogen atoms in condensed copper(I)-N,N'-di-sec-butylacetamidinate. Only upon annealing at temperatures of $150 \mathrm{~K}$ or above, after the desorption of that multilayer, does the split of the N 1s XPS signal become evident.

The copper acetamidinate chemisorbed on the $\mathrm{Ni}(110)$ surface follows its first set of chemical reactions upon annealing of the surface at temperatures as low as $200 \mathrm{~K}$. New components develop in the N 1s and C 1s XPS signals, at 399.0 and $286.0 \mathrm{eV}$, respectively. The value of the $\mathrm{N}$ 1s XPS peak, which is initially slightly higher than those seen for the original condensed copper acetamidinate and the free $N, N^{\prime}$-di-sec-butylacetamidine adsorbed on the $\mathrm{Ni}(110)$ surface (Figure 3), suggests that perhaps the acetamidinate ligand forms a new bond, or has a weaker interaction, with a nickel surface atom. Moreover, since the XPS signals associated with the new species decrease in intensity after annealing at higher temperatures and almost disappear by 300 $\mathrm{K}$, at which point $\mathrm{N}$-sec-butylacetamidine is detected in the TPD experiments, we suggest that the new species could not be the original $N, N^{\prime}$-di-sec-butylacetamidinate ligand, but a new smaller $\mathrm{N}$-sec-butylacetamidinate moiety instead. The proposed reaction would involve the scission of the $\mathrm{C}-\mathrm{N}$ bond on the imido side of the original ligand, which would be accompanied by hydrogenation of that nitrogen atom and its possible coordination to the nickel surface, and the formation of a separate sec-butyl surface moiety. The amido nitrogen of this new, smaller 
acetamidinate ligand would most likely still be coordinated to the copper center, since the copper XPS and AES data indicates the predominance of $\mathrm{Cu}(\mathrm{I})$ species in the 200-300 K temperature range. It should be said that the evidence for this pathway is not conclusive, and that it is possible for the $\mathrm{C}-\mathrm{N}$ bond to occur at the nitrogen directly bonded to the copper atom. In that case the resulting $\mathrm{N}$-sec-butylacetamidinate moiety would end up coordinated to the copper atom via its terminal nitrogen atom, the one that would also incorporate the extra hydrogen atom. The main reason why we do not propose this alternative pathway is because it would be more difficult to justify the further decomposition of the coordinated small amidinate moiety seen at higher temperatures (discussion below).

The surface $\mathrm{N}$-sec-butylacetamidinate moieties formed at $200 \mathrm{~K}$ hydrogenate, in part, to produce the $\mathrm{N}$-sec-butylacetamidine seen in the TPD at $300 \mathrm{~K}$. The hydrogen atoms required for this reaction are likely to originate from dehydrogenation of the butyl surface species, which would first undergo $\beta$-hydride elimination to produce chemisorbed 2-butene and then dehydrogenate further to surface carbon and the $\mathrm{H}_{2}$ seen at $300 \mathrm{~K}$ in the TPD. ${ }^{27,} 29,35$ It is not clear which isomer of the $\mathrm{N}$-sec-butylacetamidine is made in this step, since that depends on the identity of the nitrogen atom involved in the chemistry that occurs at $200 \mathrm{~K}$. Following the arguments provided in the previous paragraph, we propose the formation of $\mathrm{HN}=\mathrm{C}\left(\mathrm{CH}_{3}\right) \mathrm{N}(\mathrm{H})\left(\sec -\mathrm{C}_{4} \mathrm{H}_{9}\right)$ rather than $\mathrm{H}_{2} \mathrm{NC}\left(\mathrm{CH}_{3}\right)=\mathrm{N}\left(\mathrm{sec}-\mathrm{C}_{4} \mathrm{H}_{9}\right)$ in Figure 9. It is also worth noting that the $\mathrm{N}$ 1s and $\mathrm{C} 1 \mathrm{~s}$ XPS peak associated with the amidinate surface intermediate both shift to lower binding energies as this conversion occurs. 
The next major surface transformation occurs around $400 \mathrm{~K}$. At that point the old $\mathrm{N} 1 \mathrm{~s}$ and $\mathrm{C} 1 \mathrm{~s}$ XPS features shift to 398.6 and $285.4 \mathrm{eV}$, respectively, and new N 1s and C 1s XPS peaks start to grow around 397.2 and $284.0 \mathrm{eV}$, respectively. Here, the new N 1s XPS peak at $397.2 \mathrm{eV}$ is potentially identified with a nitrile surface species, and the remaining signal at $398.6 \mathrm{eV}$ with an alkylamido fragment. The reaction proposed in Figure 9 is the scission of a second $\mathrm{C}-\mathrm{N}$ bond to produce acetonitrile and a sec-butylamido surface species, in essence the reverse of one of the steps used in the synthesis of acetamides. ${ }^{17,} 36$ The identification of the acetonitrile surface intermediate is not definitive, because its desorption could not be seen in the TPD experiments, but this is not a problem, since acetonitrile desorption is not expected: such surface species is known to fully decompose on clean $\mathrm{Ni}(110) .{ }^{37}$ The small amount of $\mathrm{H}_{2}$ seen in TPD experiments at $410 \mathrm{~K}$ could originate from dehydrogenation of this product on the surface. Alternatively, the $\mathrm{N}$-sec-butylacetamidinate moiety could undergo a hydrogen transfer to the center methyl group to yield methane and a coordinated sec-butylcyanamidate $\left(\sec -\mathrm{C}_{4} \mathrm{H}_{9}-\right.$ $\mathrm{N}($ Metal $)-\mathrm{C} \equiv \mathrm{N})$ ligand, as previously reported for the decomposition of lanthanum $\operatorname{tris}\left(N, N^{\prime}\right.$-diiso-propylacetamidinate) on a lanthanum oxide surface. ${ }^{12}$ Two arguments can be offered against this pathway, though: (1) it would not account for the production of the hydrogen seen in TPD; and (2) no methane desorption was seen in any of the TPD experiments.

Finally, further decomposition of the species remaining on the surface at high temperatures is seen around $500 \mathrm{~K}$. Dehydrogenation of the sec-butyl fragment in the sec-butylamido or secbutylcyanamidate species formed at $400 \mathrm{~K}$ at its $\beta$ position may produce the butene detected in TPD, which is accompanied by the production of significant amounts of $\mathrm{H}_{2}$. This butyl moiety most likely remains bonded to the nitrogen atom until its conversion to butene, otherwise it 
would desorb or fully dehydrogenate at much lower temperatures. ${ }^{27,38}$ It should be indicated that decomposition on the nickel surface of the sec-butylamido plus acetonitrile species (or the secbutylcyanamidate species in the alternative mechanism) at $500 \mathrm{~K}$ would leave some nitrogen atoms behind on the surface, and no such nitrogen was detected in the XPS data. It may be that those nitrogen atoms hydrogenate to form ammonia, a reaction that could not be confirmed by TPD because of interference from other species, or, more likely, recombine and desorb as $\mathrm{N}_{2}{ }^{39}$, 40 If what forms on the surface is a sec-butylcyanamidate species, butene elimination would leave a cyanamidate fragment $(\mathrm{HN}($ Metal $)-\mathrm{C} \equiv \mathrm{N})$ behind, ${ }^{12}$, which, again, could either hydrogenate and desorb as cyanamide (although no evidence for this was obtained in the TPD experiments) or decompose to yield surface nitrogen and then $\mathrm{N}_{2}$. It should be said that a very different decomposition pathway has been reported recently for a related copper guanadinate precursor in the gas phase, involving the sequential formation of an oxidized guanidine first and a carbodiimide afterwards $;{ }^{13}$ no evidence for either type of products was obtained here with the acetamidinate. Lastly, in contrast to the case of nitrogen, some carbon is still seen on the surface until annealing temperatures of $700 \mathrm{~K}$, with a C 1s XPS binding energy of $284.0 \mathrm{eV}$, a value typical of $\mathrm{CH}_{\mathrm{x}}$ fragments or graphitic carbon. ${ }^{23}$ Interestingly, most of that carbon is removed from the surface upon annealing at $800 \mathrm{~K}$.

It may be valuable to place the surface chemistry uncovered here in context in terms of the use of metal amidinates as precursors in thin film deposition by chemical means, in particular in atomic layer deposition (ALD) processes. ${ }^{4}$ As mentioned in the introduction, the ligands in the metal precursors used in ALD should ideally remain intact upon adsorption at the temperatures used for film growth, and be able to react with the second reducing agent and removed cleanly from 
the surface in the second half-cycle of the ALD. Metal amidinates have been identified as potential precursors for these processes precisely because of the stability of the amidinate ligands. However, the results from our study indicate that such compounds are in fact not as stable when adsorbed on metal surfaces, where they decompose at temperatures well below those used in ALD (typically between approximately 390 and $530 \mathrm{~K}$ ). ${ }^{41}$ On the other hand, the initial decomposition reported here, which starts at temperatures as low as $200 \mathrm{~K}$, yields surface byproducts that may still be eliminated cleanly upon subsequent reactions with molecular hydrogen, ammonia, water, or hydrogen sulfide (the second reactants used in these ALD processes). Indeed, it was shown above that the scission of a $\mathrm{C}-\mathrm{N}$ bond in the original $N, N^{\prime}$-disec-butylacetamidinate ligand leads to the formation of $\mathrm{N}$-sec-butylacetamidinate and 2-butene adsorbed species. Both those products can be easily hydrogenated on metal surfaces; the first (the acetamidinate) is in fact hydrogenated to a large extent even under the conditions used here, in the absence of additional hydrogen, to the free $\mathrm{N}$-sec-butylacetamidine. If deposition of the copper acetamidinate during the first half-cycle of the ALD process were to lead to decomposition of the original ligand into a smaller amidinate and an olefin, those could still be easily removed by exposure of the surface to $\mathrm{H}_{2}$ in the second half-cycle, and clean copper films could still be grown this way. One additional interesting consequence of this chemistry is that, since most of the organic matter would be eliminated in the form of $\mathrm{N}$-sec-butylacetamidine in the first ALD half-cycle, the footprint of the adsorbed species would be greatly reduced, and deposition of more copper than what would be expected based on the surface area of the original precursor would be possible. Deposition rates as high as $\sim 0.5 \AA /$ cycle (about $20 \%$ of a monolayer/cycle) have been reported in ALD processes on metals with this precursor, ${ }^{41}$ and we have previously shown that a significantly larger copper uptake can be reached upon dosing of 
copper(I)-N,N'-di-sec-butylacetamidinate at $350 \mathrm{~K}$, a temperature above that require for $\mathrm{N}$-secbutylacetamidine desorption, than at $300 \mathrm{~K} .^{15}$ It should be noted that self-limiting uptake still occurs at $350 \mathrm{~K}$, and that temperatures above $\sim 400 \mathrm{~K}$ are still needed for the continuous deposition of copper by using the copper amidinate alone. ${ }^{15}$

Less clear is what may happen if the temperature used in ALD is high enough to promote the second set of reactions reported here. As indicated in Figure 4, the copper atoms start to be reduced on the surface at temperatures slightly above $300 \mathrm{~K}$, a change that is quite extensive by $400 \mathrm{~K}$ and complete by $500 \mathrm{~K}$. It should be highlighted that such reduction in this case occurs in the absence of any reducing agent, in what would be the first half-cycle in ALD. It is clear from our results that metal acetamidinates have the ability to undergo reduction of the metal center by themselves. In fact, self-reduction of ALD precursors has also been seen with $\mathrm{TiC}_{4},{ }^{19,}, 42,43$ $\mathrm{Ti}\left[\mathrm{N}\left(\mathrm{CH}_{3}\right)\left(\mathrm{C}_{2} \mathrm{H}_{5}\right)\right]_{4},{ }^{44} \mathrm{TaCl}_{5},{ }^{43}$ and $\mathrm{Zr}\left[\mathrm{N}\left(\mathrm{CH}_{3}\right)\left(\mathrm{C}_{2} \mathrm{H}_{5}\right)\right]_{4},{ }^{42},{ }^{43}$ all common precursors for the deposition of nitride and oxide films of those metals. ${ }^{11}$ This observation brings into question the requirement of a reducing agent for the second half of the ALD cycles. It is our contention that the main role of the second ALD reactant may be to hydrogenate and/or desorb the organic fragments that may form on the surface during the precursor reactions in the first half of the ALD cycle, not to reduce the metal center, something that may have already taken place immediately upon adsorption.

In view of this emphasis of the need to use a hydrogenation agent in the second half of the ALD cycle, it is particularly important to identify the thermal chemistry of the ALD precursor and to evaluate the feasibility of being able to remove any possible intermediates that may form on the 
surface. In connection with that, our studies with the copper acetamidinate precursor indicate that heating to $\sim 400 \mathrm{~K}$ already results in the dissociation of the smaller $\mathrm{N}$-sec-butylacetamidinate moiety formed at $200 \mathrm{~K}$, possibly into nitrile and alkylamido surface species (Figure 9). It could still be possible to displace the nitrile from the surface by $\mathrm{H}_{2}$ in the second half of the ALD process, a reaction that is perhaps more likely on smother low-Miller-index planes, ${ }^{37}$ and also to hydrogenate the alkylamido species to the free alkylamine, but these reactions may be more difficult and may not occur to completion. However, by approximately $485 \mathrm{~K}$, further dissociation of the alkylamido surface species occurs, releasing an olefin (butene in our case) and leaving $\mathrm{NH}_{\mathrm{x}}$ species on the surface, and the latter adsorbates would be quite difficult to remove. Furthermore, additional dehydrogenation occurs above $\sim 500 \mathrm{~K}$, and at that stage it would be certain that some carbon would be left behind on the growing metal film. We have already reported that by $480 \mathrm{~K}$ the deposition of copper films using the copper amidinate precursor along is no longer self-limiting, and continues indefinitely with increasing exposures. ${ }^{15}$ That is a definitive threshold temperature to avoid the deposition of carbon impurities.

Based on the surface chemistry described above, it could be concluded that the ALD of copper films using copper amidinates should be conducted at as low a temperature as possible. Certainly, a monolayer of copper can be deposit this way at temperatures as low as $350 \mathrm{~K} .^{15}$ However, other considerations, including the crystallinity of the films and their electrical properties, may demand the use of higher temperatures. ${ }^{41}$ It has been shown that films grown at $463 \mathrm{~K}$ do not incorporate measurable amounts of carbon, ${ }^{41}$ suggesting that even the nitrile and alkylamido species that may form at that temperature may be removed from the surface upon treatment with $\mathrm{H}_{2}$. This provides a temperature window, perhaps between approximately 460 
and $500 \mathrm{~K}$, where this type of ALD is viable. It should be said that previous studies in our laboratory have indicated that the use of temperatures above $450 \mathrm{~K}$ lead to the continuous conversion of the copper acetamidinate on the surface, which means that deposition would not be strictly via an ALD process above that temperature. ${ }^{15}$ In any case, the use of temperatures above $500 \mathrm{~K}$ would almost surely lead to the deposition of some carbon in the growing films.

\section{Conclusions}

The thermal chemistry of $N, N^{\prime}$-di-sec-butylacetamidinate on Ni(110) single-crystal surfaces has been characterized by XPS and TPD. The conversion of $\mathrm{Cu}(\mathrm{I})$ to $\mathrm{Cu}(0)$ species was detected over a range of temperatures, between 300 and $500 \mathrm{~K}$. This is accompanied by a decrease in the $\mathrm{N}$ 1s and $\mathrm{C} 1 \mathrm{~s}$ XPS signals associated with the $N, N^{\prime}$-di-sec-butylacetamidinate ligands and the appearance of a number of new features in those spectra. In addition, the TPD experiments were used to identify the formation of a smaller acetamidine, $\mathrm{N}$-sec-butylacetamidine, and butene, at 300 and $500 \mathrm{~K}$ respectively. The combined XPS and TPD data were used to propose the reaction scheme shown in Figure 9. Four main stages of conversion were isolated: (1) the dissociative chemisorption of the copper acetamidinate dimer on the metal surface, which occurs at temperatures as low as $90 \mathrm{~K}$; (2) the dissociation of the $N, N^{\prime}$-di-sec-butylacetamidinate ligand into $\mathrm{N}$-sec-butylacetamidinate and butene at $200 \mathrm{~K}$ (and the hydrogenation of the former to $\mathrm{N}$ sec-butylacetamide at $300 \mathrm{~K}$ ); (3) the dissociation of the $\mathrm{N}$-sec-butylacetamidinate that remains on the surface at $400 \mathrm{~K}$, possibly into acetonitrile and a sec-butylamido surface species; and (4) the elimination of butene from the alkylamido intermediate and the further dehydrogenation of 
the remaining adsorbates around $500 \mathrm{~K}$. All but the latter stage produce surface species that can potentially be removed by hydrogenation with $\mathrm{H}_{2}$. On the other hand, the occurrence of the final decomposition of the surface species at $500 \mathrm{~K}$ sets an upper limit for the use of this compound as a precursor in the deposition of clean copper films by ALD processes.

\section{Acknowledgements}

Funding for this project was provided by the U. S. Department of Energy. 


\section{References}

1. Barker, J.; Kilner, M., Coord. Chem. Rev. 1994, 133, 219.

2. Coles, M. P., Dalton Trans. 2006, 985.

3. Edelmann, F. T., Chapter 3 Advances in the Coordination Chemistry of Amidinate and Guanidinate Ligands. In Advances in Organometallic Chemistry, Anthony, F. H.; Mark, J. F., Eds. Academic Press: 2008; Vol. Volume 57, pp 183.

4. Lim, B. S.; Rahtu, A.; Gordon, R. G., Nature Mater. 2003, 2, 749.

5. Lim, B. S.; Rahtu, A.; Park, J. S.; Gordon, R. G., Inorg. Chem. 2003, 42, 7951.

6. Wiedmann, M. K.; Heeg, M. J.; Winter, C. H., Inorg. Chem. 2009, 48, 5382.

7. Krisyuk, V.; Gleizes, A. N.; Aloui, L.; Turgambaeva, A.; Sarapata, B.; Prud'Homme, N.; Senocq, F.; Samelor, D.; Zielinska-Lipiec, A.; de Caro, D.; Vahlas, C., J. Electrochem. Soc. 2010, 157, D454.

8. Xu, K.; Milanov, A. P.; Winter, M.; Barreca, D.; Gasparotto, A.; Becker, H. W.; Devi, A., European Journal of Inorganic Chemistry 2010, 1679.

9. $\quad$ Leskelä, M.; Ritala, M., Angew. Chem., Int. Ed. 2003, 42, 5548.

10. Putkonen, M.; Niinistö, L., Top. Organomet. Chem. 2005, 9, 125.

11. Zaera, F., J. Mater. Chem. 2008, 18, 3521.

12. Kwon, J.; Dai, M.; Halls, M. D.; Langereis, E.; Chabal, Y. J.; Gordon, R. G., J. Phys. Chem. C 2009, 113, 654.

13. Coyle, J. P.; Johnson, P. A.; DiLabio, G. A.; Barry, S. T.; Müller, J., Inorg. Chem. 2010, $49,2844$.

14. Dai, M.; Kwon, J.; Halls, M. D.; Gordon, R. G.; Chabal, Y. J., Langmuir 2010, 26, 3911. 
15. Ma, Q.; Guo, H.; Gordon, R. G.; Zaera, F., Chem. Mater. 2010, 22, 352.

16. Chrysostomou, D.; Flowers, J.; Zaera, F., Surf. Sci. 1999, 439, 34.

17. Li, Z.; Barry, S. T.; Gordon, R. G., Inorg. Chem. 2005, 44, 1728.

18. Wagner, C. D.; Riggs, W. M.; Davis, L. E.; Moulder, J. F.; Muilenberg, G. E., Handbook of X-Ray Photoelectron Spectroscopy. Perkin-Elmer Corporation: Eden Prairie, MN, 1978.

19. Tiznado, H.; Zaera, F., J. Phys. Chem. B. 2006, 110, 13491.

20. Wagner, C. D.; Naumkin, A. V.; Kraut-Vass, A.; Allison, J. W.; Powell, C. J.; Rumble, J. R., Jr. NIST X-ray Photoelectron Spectroscopy Database. http://srdata.nist.gov/xps/

21. Kishi, K.; Okino, Y.; Fujimoto, Y., Surf. Sci. 1986, 176, 23.

22. Sexton, B. A.; Avery, N. R., Surf. Sci. 1983, 129, 21.

23. Wiltner, A.; Linsmeier, C., Phys. Status Solidi A 2004, 201, 881.

24. Christmann, K.; Schober, O.; Ertl, G.; Neumann, M., J. Chem. Phys. 1974, 60, 4528.

25. Guo, H.; Zaera, F., Surf. Sci. 2003, 547, 284.

26. Guo, H.; Zaera, F., J. Phys. Chem. B 2004, 108, 16220.

27. Zaera, F., Chem. Rev. 1995, 95, 2651.

28. Tjandra, S.; Zaera, F., J. Am. Chem. Soc. 1995, 117, 9749.

29. Ma, Z.; Zaera, F., Surf. Sci. Rep. 2006, 61, 229.

30. Kaloyeros, A. E.; Eisenbraun, E., Annu. Rev. Mater. Sci. 2000, 30, 363.

31. Beyer, G.; Satta, A.; Schuhmacher, J.; Maex, K.; Besling, W.; Kilpela, O.; Sprey, H.; Tempel, G., Microelectron. Eng. 2002, 64, 233.

32. Goswami, I.; Laxman, R., Semiconductor Int. 2004, 27, 49. 
33. O'Sullivan, E. J.; Schrott, A. G.; Paunovic, M.; Sambucetti, C. J.; Marino, J. R.; Bailey, P. J.; Kaja, S.; Semkow, K. W., IBM. J. Res. Develop. 1998, 42, 607.

34. Li, Z.; Gordon, R. G.; Farmer, D. B.; Lin, Y.; Vlassak, J., Electrochem. Solid State Lett. 2005, 8, G182.

35. Lee, I.; Zaera, F., J. Phys. Chem. B 2005, 109, 2745.

36. Forsberg, J. H.; Spaziano, V. T.; Balasubramanian, T. M.; Liu, G. K.; Kinsley, S. A.; Duckworth, C. A.; Poteruca, J. J.; Brown, P. S.; Miller, J. L., J. Org. Chem. 1987, 52, 1017.

37. Friend, C. M.; Stein, J.; Muetterties, E. L., J. Am. Chem. Soc. 1981, 103, 767.

38. Tjandra, S.; Guo, H.; Zaera, F., Top. Catal. 2011, 54, 26.

39. Chorkendorff, I.; Russell, J. N., Jr.; Yates, J. T., Jr., J. Chem. Phys. 1987, 86, 4692.

40. Gardin, D. E.; Somorjai, G. A., J. Phys. Chem. 1992, 96, 9424.

41. Li, Z.; Rahtu, A.; Gordon, R. G., J. Electrochem. Soc. 2006, 153, C787.

42. Xu, M.; Tiznado, H.; Kang, B.-C.; Bouman, M.; Lee, I.; Zaera, F., J. Kor. Phys. Soc. 2007, 51, 1063.

43. Tiznado, H.; Bouman, M.; Kang, B.-C.; Lee, I.; Zaera, F., J. Mol. Catal. A 2008, 281, 35.

44. Bouman, M.; Zaera, F., ECS Trans. 2010, 33, 291. 


\section{Tables}

Table 1. Fitting parameters for the N 1s XPS peaks shown in the left panel of Figure 2. Up to four Gaussian peaks were fitted to each trace after background subtraction. The binding energies (BE) and peak widths (w) were fixed for the complete set, and only the amplitudes (A) were fitted to each individual spectrum. The optimized parameters are indicated by bold characters.

\begin{tabular}{|c|c|c|c|c|c|c|c|c|c|c|c|c|}
\hline \multirow[b]{2}{*}{$\mathrm{T} / \mathrm{K}$} & \multicolumn{3}{|c|}{ Peak 1} & \multicolumn{3}{|c|}{ Peak 2} & \multicolumn{3}{|c|}{ Peak 3} & \multicolumn{3}{|c|}{ Peak 4} \\
\hline & $\mathrm{BE} / \mathrm{eV}$ & $\mathbf{A} / \mathbf{c p s}$ & $\mathrm{w} / \mathrm{eV}$ & $\mathrm{BE} / \mathrm{eV}$ & $\mathbf{A} / \mathbf{c p s}$ & $\mathrm{w} / \mathrm{eV}$ & $\mathrm{BE} / \mathrm{eV}$ & A/cps & $\mathrm{w} / \mathrm{eV}$ & $\mathrm{BE} / \mathrm{eV}$ & $\mathbf{A} / \mathbf{c p s}$ & w/eV \\
\hline 90 & 398.70 & 175.25 & 0.90 & 400.10 & 110.84 & 1.00 & & & & & & \\
\hline 150 & 398.65 & 155.99 & 0.90 & 400.15 & 157.75 & 0.88 & & & & & & \\
\hline 200 & 398.65 & 115.43 & 0.90 & 400.15 & 116.74 & 0.88 & 399.00 & 41.35 & 0.85 & & & \\
\hline 250 & 398.65 & 93.60 & 0.90 & 400.15 & 94.65 & 0.88 & 399.00 & 58.63 & 0.85 & & & \\
\hline 300 & 398.65 & 78.00 & 0.90 & 400.15 & 78.88 & 0.88 & 398.90 & 54.74 & 0.85 & 397.20 & 11.14 & 0.80 \\
\hline 400 & 398.65 & 42.12 & 0.90 & 400.15 & 42.59 & 0.88 & 398.60 & 75.51 & 0.85 & 397.20 & 29.54 & 0.80 \\
\hline 500 & 398.65 & 10.92 & 0.90 & 400.15 & 11.04 & 0.88 & 398.60 & 36.91 & 0.85 & 397.20 & 25.87 & 0.80 \\
\hline 600 & 398.65 & 6.24 & 0.90 & 400.15 & 6.31 & 0.88 & 398.60 & 18.72 & 0.85 & 397.20 & 7.42 & 0.80 \\
\hline 700 & 398.65 & & & 400.15 & & & 398.60 & 6.26 & 0.85 & 397.20 & 2.58 & 0.80 \\
\hline
\end{tabular}


Table 2. Fitting parameters for the C 1s XPS peaks shown in the right panel of Figure 2. Up to five Gaussian peaks were fitted to each trace after background subtraction. The binding energies (BE) and peak widths (w) were fixed for the complete set, and only the amplitudes (A) were fitted to each individual spectrum. In addition, the integrated areas of the first three peaks, assigned to the original copper amidinate, were fixed to follow ratios of 7:2:1. The optimized parameters are indicated by bold characters.

\begin{tabular}{|c|c|c|c|c|c|c|c|c|c|c|c|c|c|c|c|}
\hline \multirow[b]{2}{*}{$\mathrm{T} / \mathrm{K}$} & \multicolumn{3}{|c|}{ Peak 1} & \multicolumn{3}{|c|}{ Peak 2} & \multicolumn{3}{|c|}{ Peak 3} & \multicolumn{3}{|c|}{ Peak 4} & \multicolumn{3}{|c|}{ Peak 5} \\
\hline & $\mathrm{BE} / \mathrm{eV}$ & A/cps & $\mathrm{w} / \mathrm{eV}$ & $\mathrm{BE} / \mathrm{eV}$ & $\mathrm{A} / \mathrm{cps}$ & $\mathrm{w} / \mathrm{eV}$ & $\mathrm{BE} / \mathrm{eV}$ & $\mathrm{A} / \mathrm{cps}$ & $\mathrm{w} / \mathrm{eV}$ & $\mathrm{BE} / \mathrm{eV}$ & A/cps & $\mathrm{w} / \mathrm{eV}$ & $\mathrm{BE} / \mathrm{eV}$ & A/cps & $\mathrm{w} / \mathrm{eV}$ \\
\hline 90 & 285.40 & 638.57 & 0.82 & 286.40 & 182.45 & 0.82 & 287.50 & 91.22 & 0.82 & & & & & & \\
\hline 150 & 285.40 & 619.61 & 0.96 & 286.40 & 177.03 & 0.96 & 287.50 & 88.52 & 0.96 & & & & & & \\
\hline 200 & 285.40 & 433.73 & 0.96 & 286.40 & 123.92 & 0.96 & 287.50 & 61.96 & 0.96 & 287.60 & 41.40 & 0.80 & 286.00 & 182.87 & 0.80 \\
\hline 250 & 285.40 & 402.75 & 0.96 & 286.40 & 115.07 & 0.96 & 287.50 & 57.54 & 0.96 & 284.20 & 23.72 & 0.90 & 285.60 & 74.02 & 0.80 \\
\hline 300 & 285.40 & 325.29 & 0.96 & 286.40 & 92.94 & 0.96 & 287.50 & 46.47 & 0.96 & 284.20 & 59.35 & 0.90 & 285.50 & 40.62 & 0.80 \\
\hline 400 & 285.40 & 179.69 & 0.96 & 286.40 & 51.34 & 0.96 & 287.50 & 25.67 & 0.96 & 284.20 & 108.80 & 0.90 & 285.50 & 130.62 & 0.80 \\
\hline 500 & 285.40 & 61.96 & 0.96 & 286.40 & 17.70 & 0.96 & 287.50 & 8.85 & 0.96 & 283.90 & 143.12 & 0.90 & 285.40 & 66.40 & 0.90 \\
\hline 600 & 285.40 & 30.98 & 0.96 & 286.40 & 8.85 & 0.96 & 287.50 & 4.43 & 0.96 & 283.90 & 148.48 & 0.90 & 285.40 & 19.95 & 0.90 \\
\hline 700 & 285.40 & 18.59 & 0.96 & 286.40 & 5.31 & 0.96 & 287.50 & 2.66 & 0.96 & 283.90 & 130.60 & 0.90 & 285.40 & 37.03 & 0.90 \\
\hline 800 & & & & & & & & & & 283.90 & 28.08 & 0.90 & 285.40 & 16.14 & 0.90 \\
\hline
\end{tabular}




\section{Figure Captions}

Figure 1. $\mathrm{Cu} 2 \mathrm{p}_{3 / 2}$ XPS (left) and $\mathrm{Cu} \mathrm{L}{ }_{3} \mathrm{VV}$ Auger (right) data for a Ni(110) single-crystal surface dosed with $50 \mathrm{~L}$ of copper(I)- $N, N^{\prime}$-di-sec-butylacetamidinate at $90 \mathrm{~K}$ as a function of subsequent annealing temperature. A single conversion from $\mathrm{Cu}(\mathrm{I})$ to $\mathrm{Cu}(0)$ is seen at about $400 \mathrm{~K}$.

Figure 2. $\mathrm{N}$ 1s (left) and $\mathrm{C}$ 1s (right) XPS data for $50 \mathrm{~L}$ of copper(I)- $N$, $N$ '-di-secbutylacetamidinate dosed on $\mathrm{Ni}(110)$ at $90 \mathrm{~K}$ as a function of subsequent annealing temperature. The raw data are reported as dots; the solid lines correspond to the overall fits to Gaussian peaks according to the parameters provided in Tables 2 and 3.

Figure 3. N 1s (left) and C 1s (right) reference XPS data. Shown are traces for $15 \mathrm{~L}$ (bottom) and $50 \mathrm{~L}$ (second from bottom) of copper(I)-N,N'-di-sec-butylacetamidinate (CuAMD) and for $50 \mathrm{~L}$ of $N, N^{\prime}$-di-sec-butylacetamidine (amidine, third from bottom), all dosed on $\mathrm{Ni}(110)$ at $90 \mathrm{~K}$. The top three traces correspond to subtraction spectra offered to highlight specific changes in this system. From bottom to top, they correspond to the difference between the $50 \mathrm{~L}$ copper acetamidinate at $90 \mathrm{~K}$ and: the same surface after annealing to $150 \mathrm{~K}$, the data for $15 \mathrm{~L}$ of the copper acetamidinate adsorbed at $90 \mathrm{~K}$, and the trace for $50 \mathrm{~L}$ of the free amidine adsorbed at $90 \mathrm{~K}$. Also shown are the fits obtained for each trace, as discussed in the text. 
Figure 4. Summary of XPS data for $50 \mathrm{~L}$ of copper(I)- $N, N^{\prime}$-di-sec-butylacetamidinate dosed on $\mathrm{Ni}(110)$ at $90 \mathrm{~K}$ as a function of subsequent annealing temperature. Estimated surface coverages are reported for the different copper (left), carbon (center), and nitrogen (right) species deconvoluted from the raw data in Figures 1 and 2 according to the parameters in Tables 1 and 2.

Figure 5. Survey TPD data for $20 \mathrm{~L}$ of copper(I)-N,N'-di-sec-butylacetamidinate dosed on $\mathrm{Ni}(110)$ at $90 \mathrm{~K}$. Traces are shown for the desorption of the main products detected in the gas phase, namely (from top to bottom): molecular hydrogen, butene, $\mathrm{N}$-secbutylacetamidine, and the original copper(I)-N,N'-di-sec-butylacetamidinate. The signals for 2, 56, 114 and $72 \mathrm{amu}$ were used to follow the these products, respectively.

Figure 6. Evidence for the identification of the compound that desorbs at $300 \mathrm{~K}$ in the TPD in Figure 5 as $\mathrm{N}$-sec-butylacetamidine. Main Frame: TPD traces for selected masses $(112,114,154,155$, and $170 \mathrm{amu})$. Inset: relative intensities for the two (215 and $300 \mathrm{~K}$ ) peaks seen in the TPD traces for all masses between 106 and $114 \mathrm{amu}$. The different cracking patterns seen for the two peaks point to the formation of different species in those two temperature ranges. The maximum mass for which signal is seen in the second $(300 \mathrm{~K})$ TPD peak, $114 \mathrm{amu}$, corresponds to the molecular weight of $\mathrm{N}$ sec-butylacetamidine. 
Figure 7. TPD traces for the main products from thermal activation of copper(I)- $N, N^{\prime}$-di-secbutylacetamidinate on $\mathrm{Ni}(110)$ as a function of initial dose at $90 \mathrm{~K}$.

Figure 8. $\mathrm{N} 1 \mathrm{~s}$ (left) and $\mathrm{C} 1 \mathrm{~s}$ (right) XPS data for $15 \mathrm{~L}$ of copper(I)- $N, N^{\prime}$-di-secbutylacetamidinate dosed on a cobalt polycrystalline foil at $90 \mathrm{~K}$ as a function of subsequent annealing temperature.

Figure 9. Schematic depiction of the main reactions proposed for the thermal chemistry of copper(I)- $N, N^{\prime}$-di-sec-butylacetamidinate adsorbed on the nickel and cobalt surfaces. 


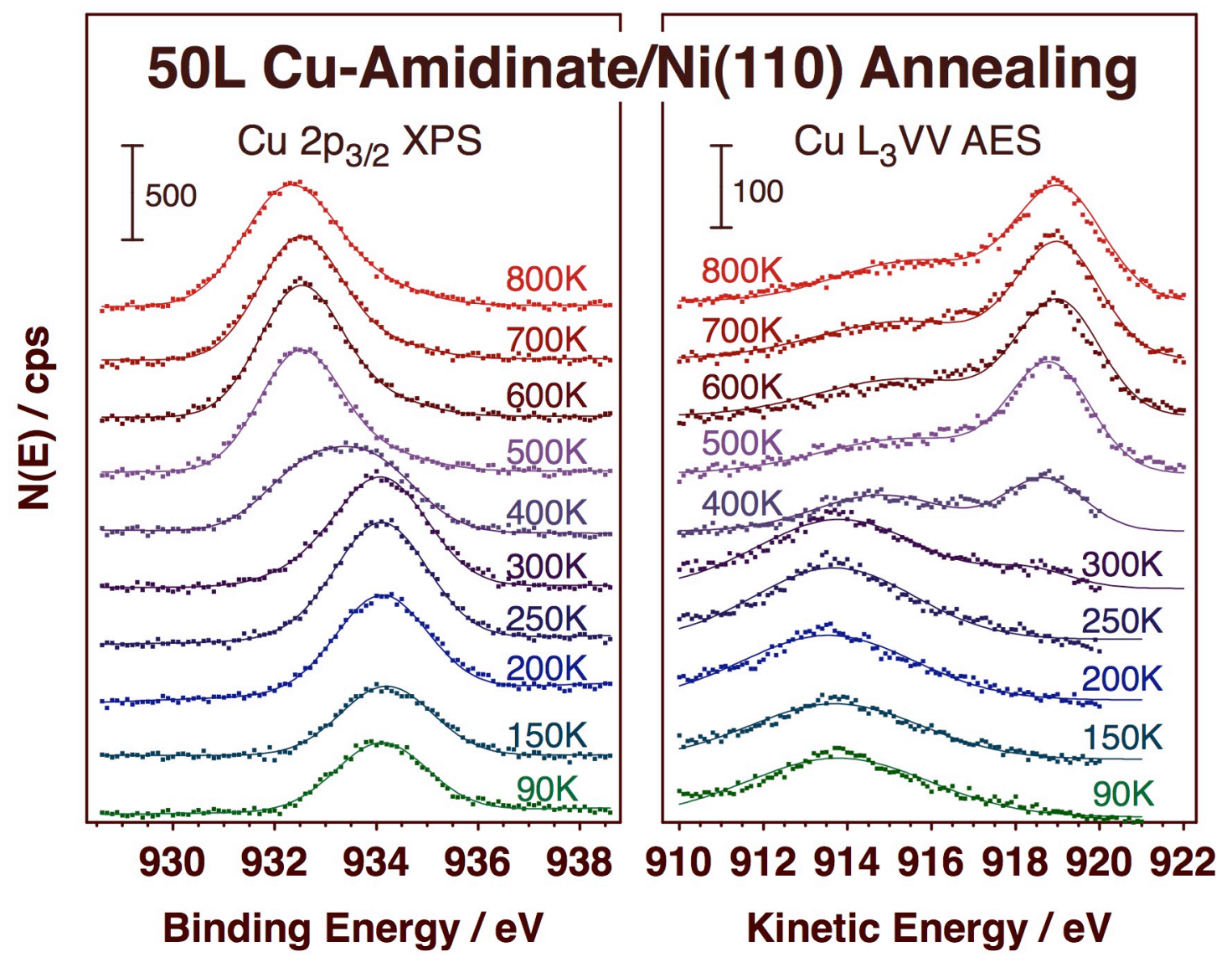

Figure 1 


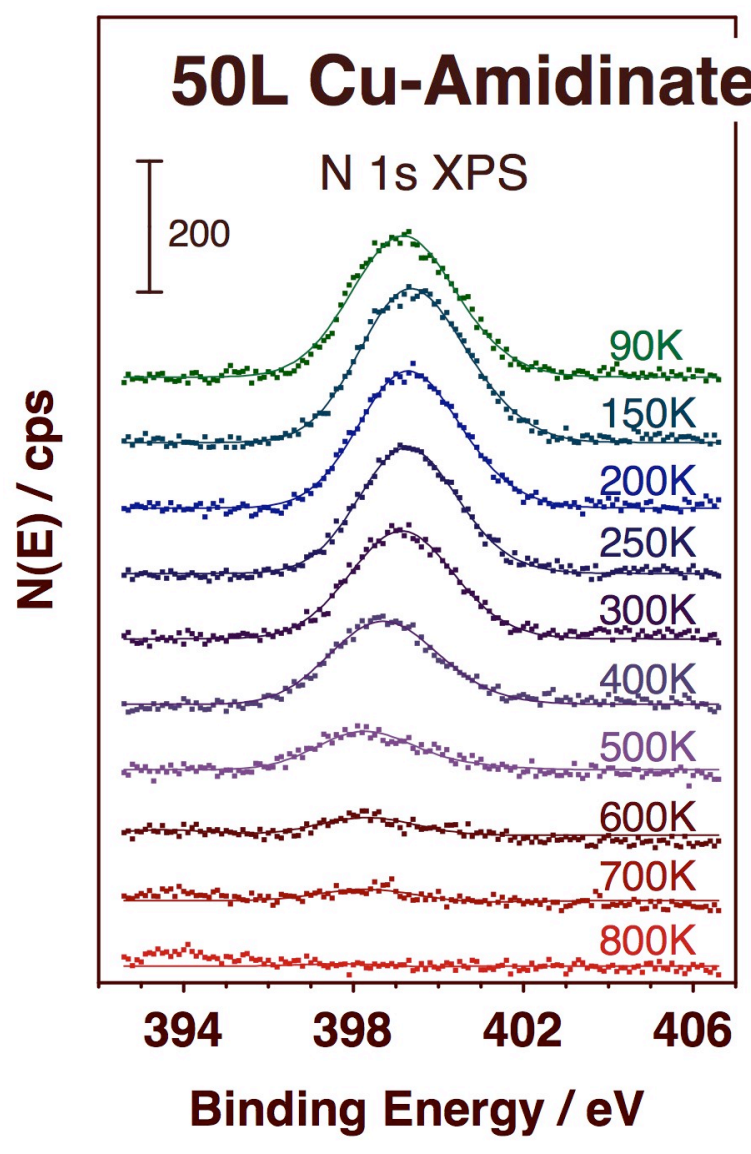

\section{Ni(110) Annealing}

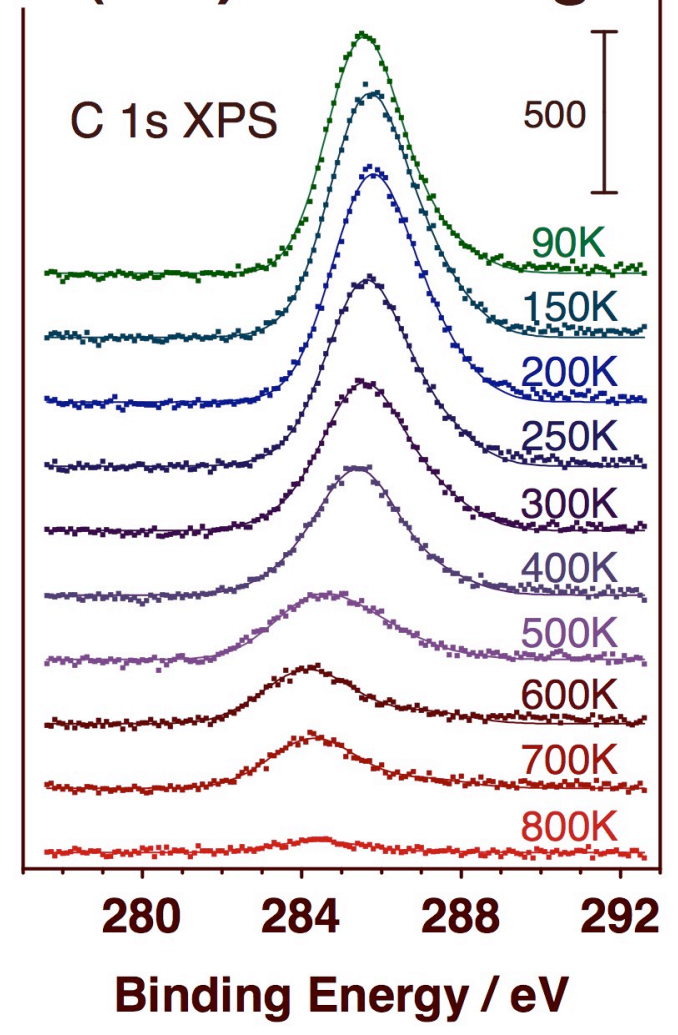

Figure 2 


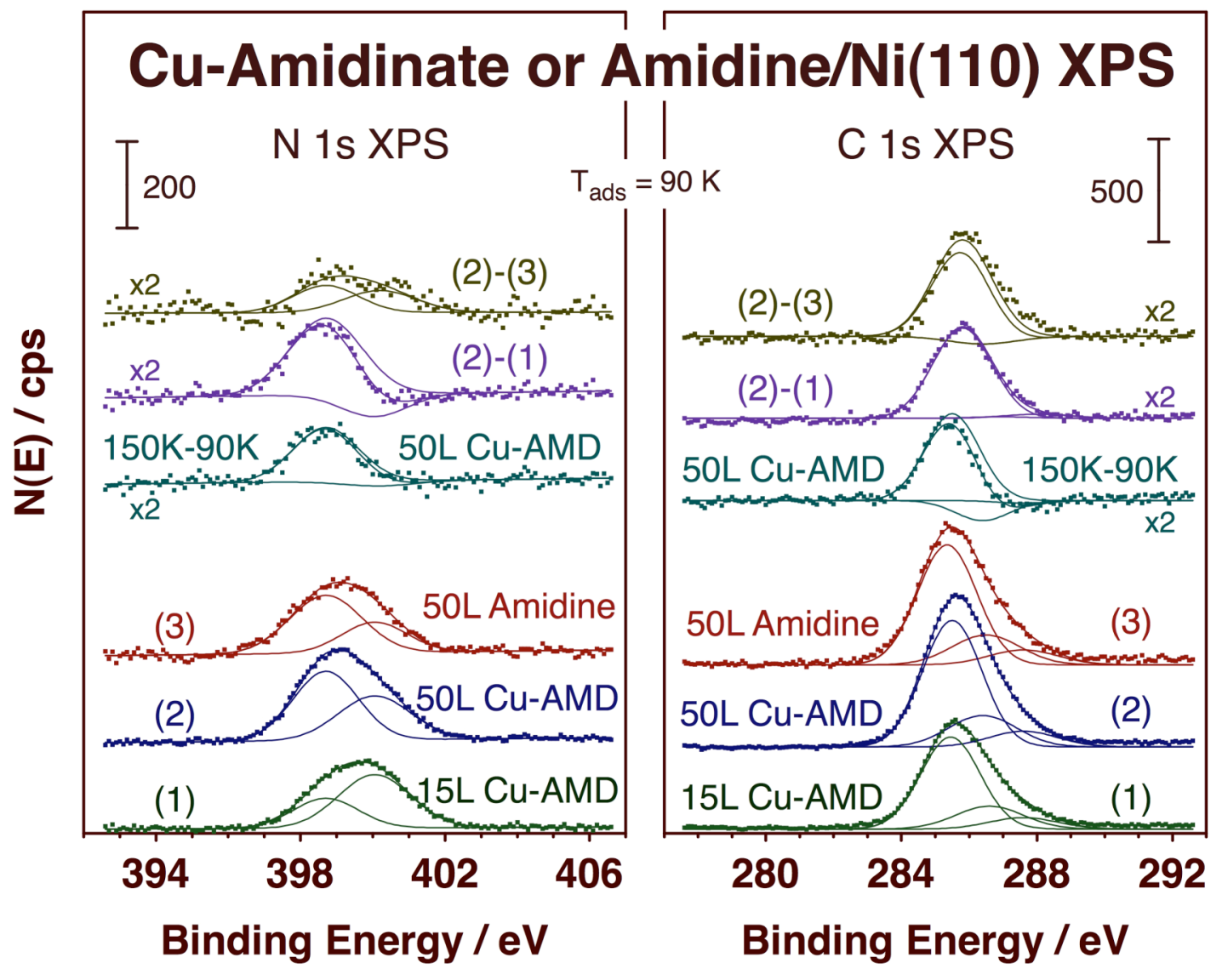

Figure 3 


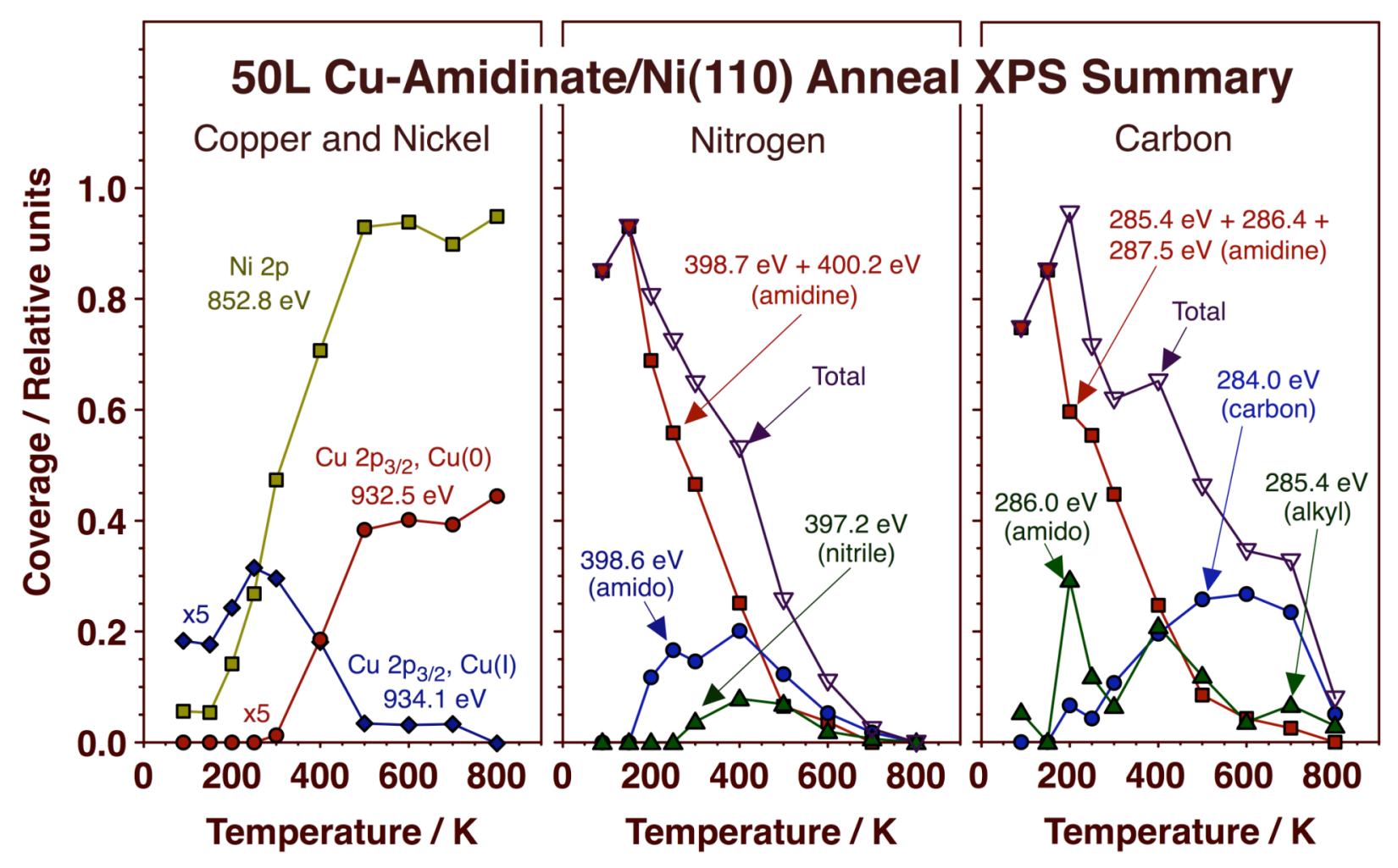

Figure 4 


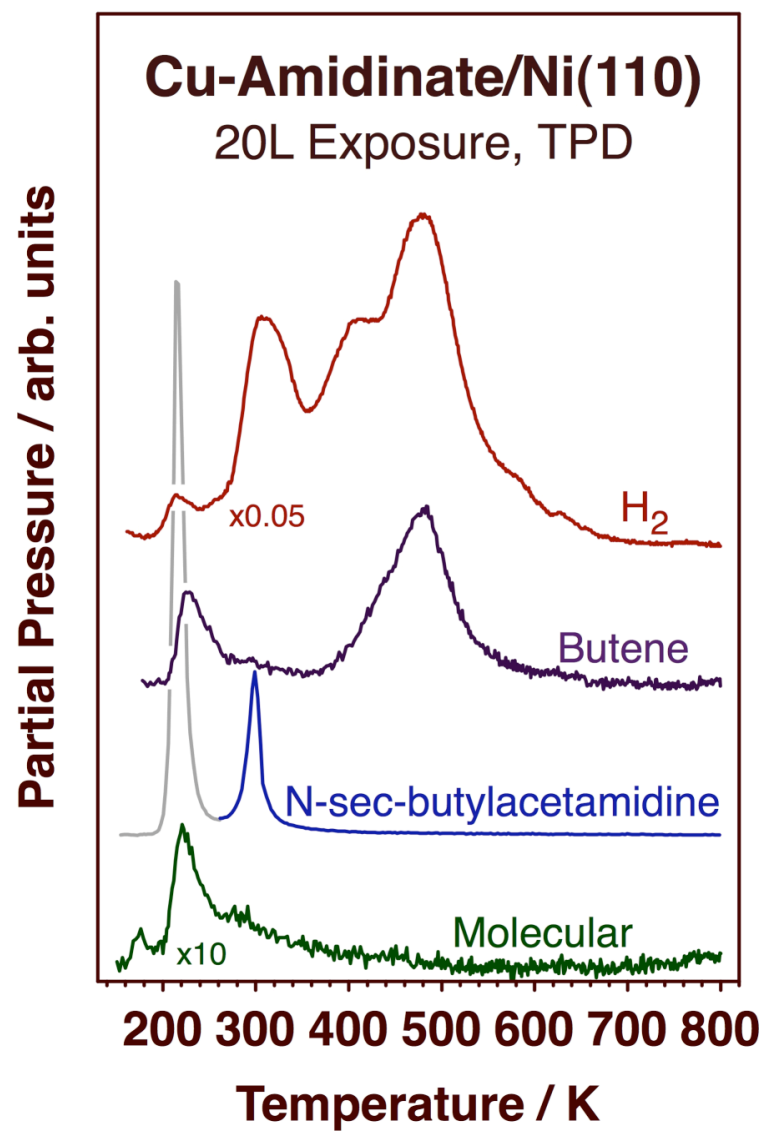

Figure 5 


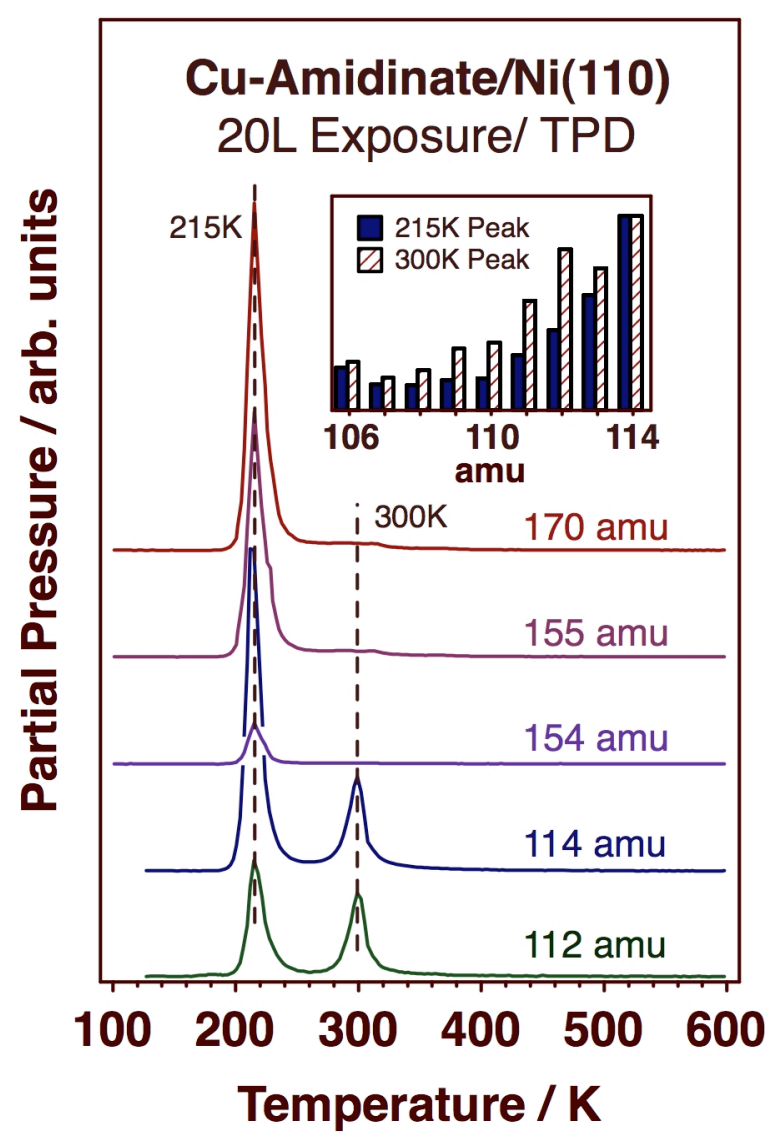

Figure 6 


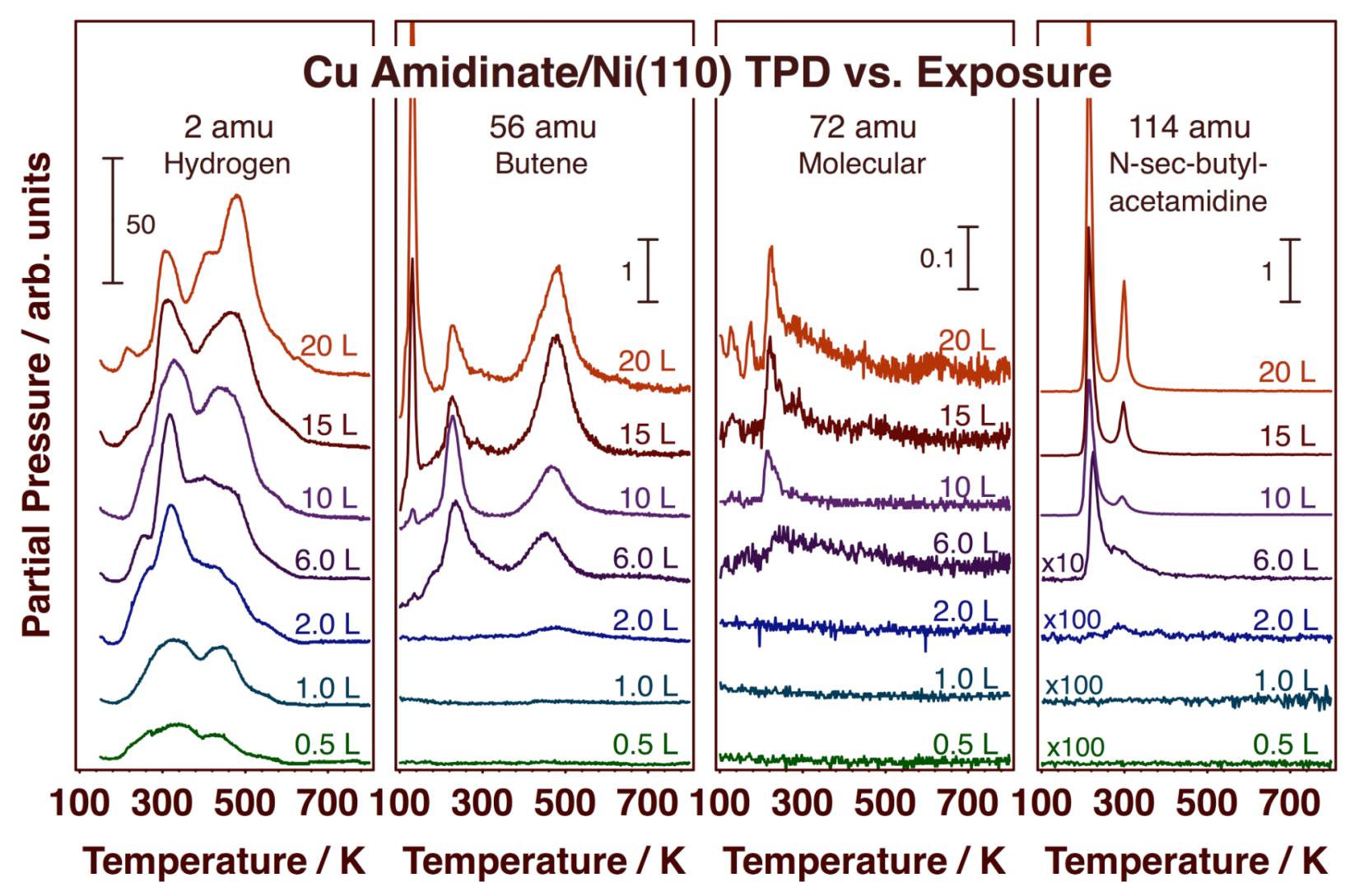

Figure 7 


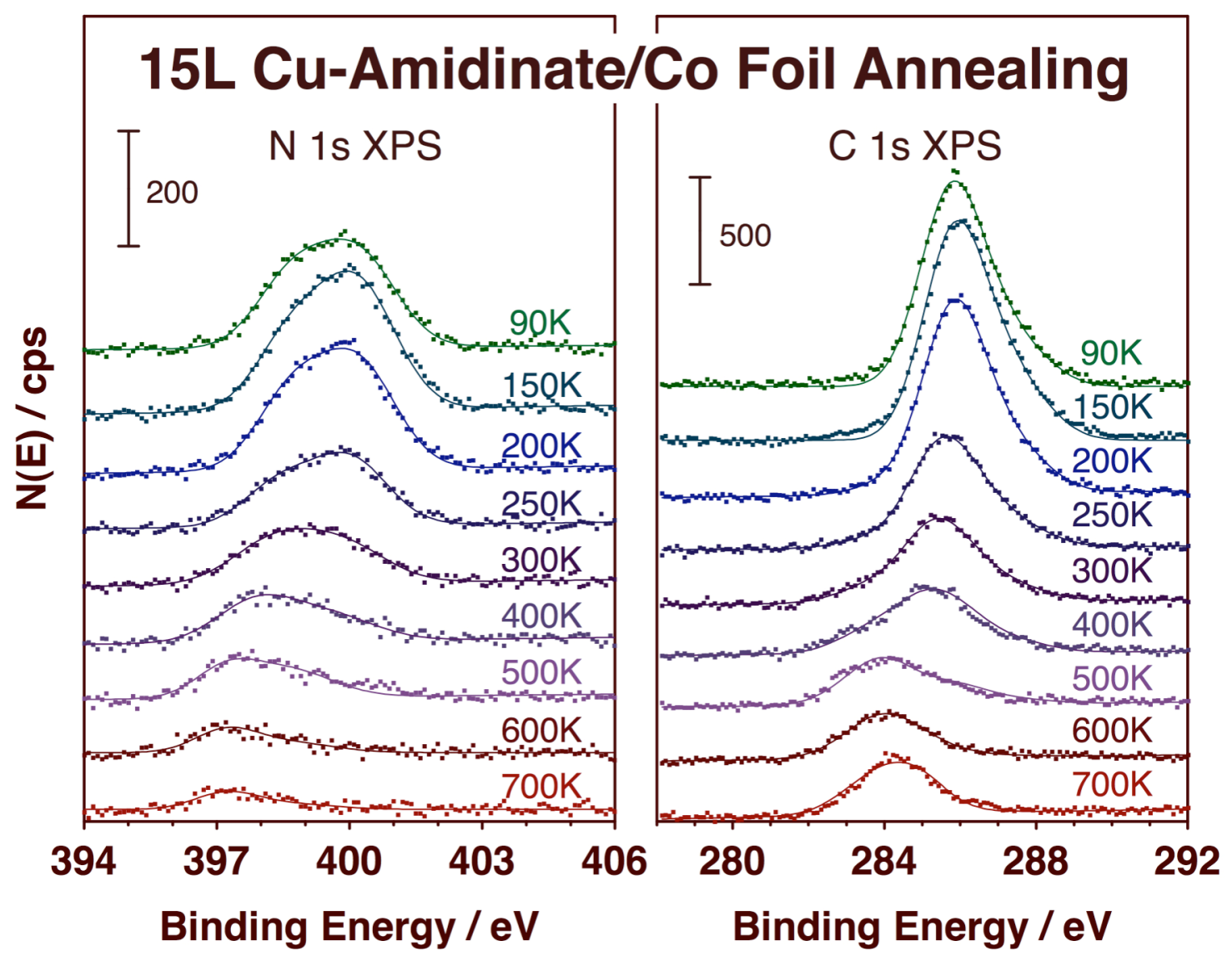

Figure 8 


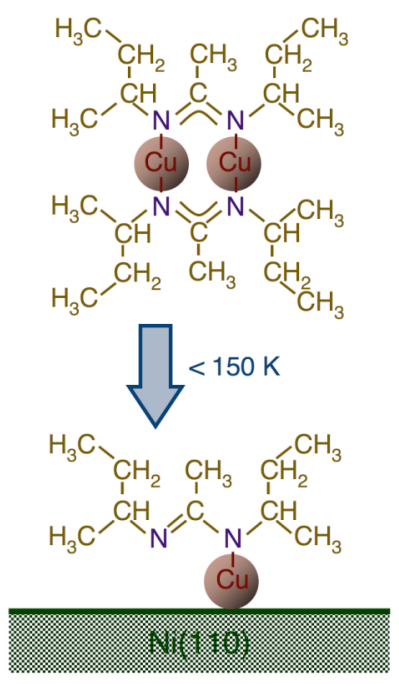

\section{Cu Acetamidinate/Ni(110) Thermal Conversion}

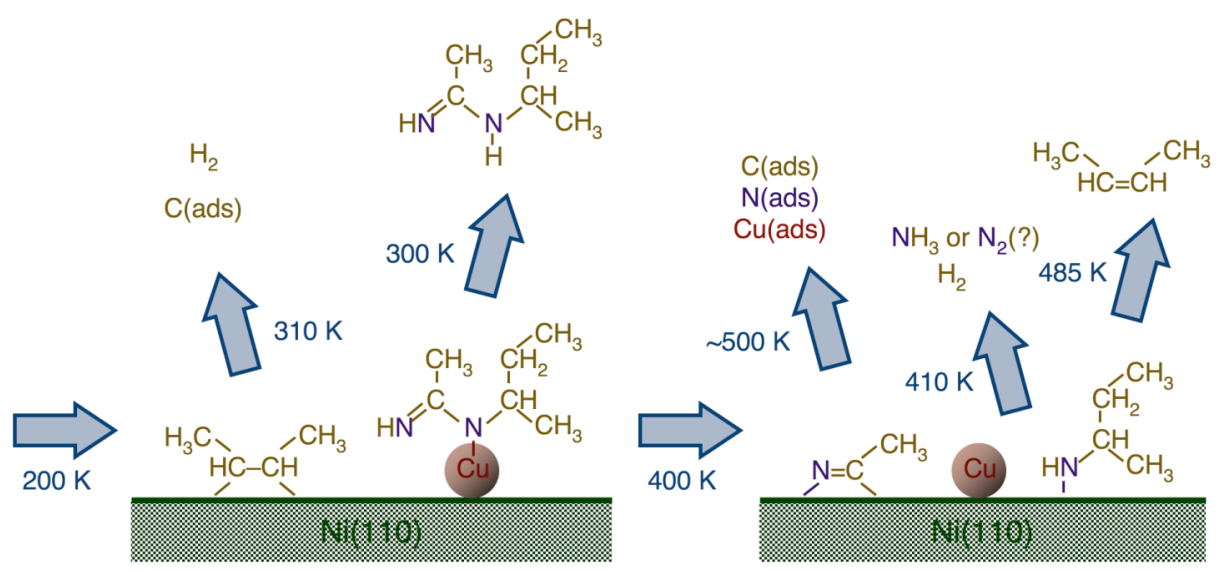

Figure 9 


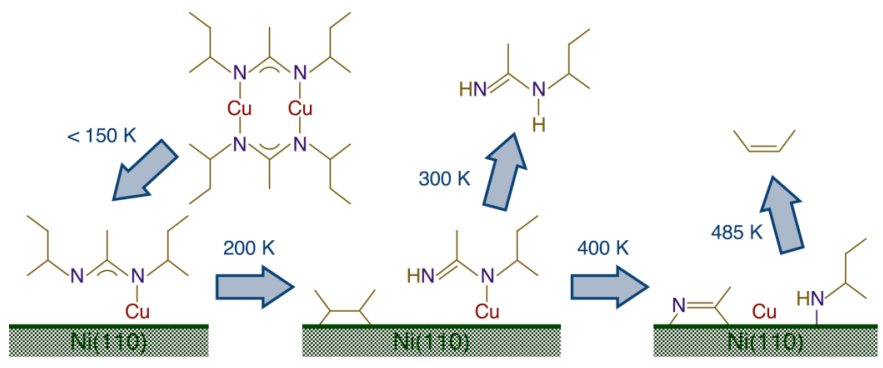

TOC

The surface chemistry of copper(I)-N,N'-di-sec-butylacetamidinate, a promising precursor for thin film deposition, is complex. It involves an initial dimer-to-monomer conversion, and the stepwise decomposition of the organic ligands, to a small amidinate around $200 \mathrm{~K}$ and to more dehydrogenated species, butene and possibly acetonitrile, above $400 \mathrm{~K}$. 